\title{
LOS PERROS EN LA PINTURA
}

\author{
por F. Morales PAdRON
}

\begin{abstract}
Inspirándose en una pintura anónima flamenca que representa a doña Juana y a la infanta Isabel rodeadas de 42 perros, al autor analiza con ejemplos la presencia del perro, cual constante (tal vez por ser considerado el mejor amigo), en la pintura de todas las épocas. Son perros de variadas razas que figuran solos o en unión de otros animales de su especie en acciones de cacería, aperreamiento de seres humanos o acompañando al hombre como parte de la acción representada o como elemento omamental o de relleno.

Incluso en la pictografía religiosa referida a la Pasión los artistas no se han olvidado del perro.
\end{abstract}

Inspired by an anonymous Flemish painting showing Doña Juana and the Infanta Isabel surrounded by forty-two dogs, the author analyses, with examples, the constant presence of dogs (possibly due to their being regarded as man's best friend) in paintings from all periods. Dogs of various breeds appear individually or in groups, represented as participating in the hunt, being set on human beings or accompanying man in the activity depicted, or else to adorn or fill in the canvas.

Even in the religious imagery of the Passion, dogs have not been forgotten.

El tema es inacabable y, de seguro, que alguien lo ha abordado ya con maestría y conocimiento. Aquí se recogen las observaciones de un profano, que, a partir de un cuadro que contempló en la Europalia 85 (Bruselas) fue anotando la presencia del perro en cuanto cuadro le fue dado conocer, creyendo observar que los canes son los animales que mas figuran al lado del ser humano en la producción pictórica. En otra ocasión nos aficionamos a coleccionar el tema "Los puertos en la pintura".

El perro acompaña al hombre desde las cavernas de la Prehistoria. Su inteligencia y su apego le convierten en el ser más cercano a la vida cotidiana de los dotados de razón. Al igual que el caballo o el cordero son animales que se prodigan en la pintura o en la heráldica. Tal vez sea su fidelidad -eso que exigimos a los demás y consideramos bien preciado- lo que le convierte en compañero entrañable y en tema pictórico con una mayor o menor presencia según artistas y no según épocas, porque en todas se encuentra presente el can dentro de los lienzos. Influye o determina su aparición el tema del cuadro y el 
mismo entorno familiar del pintor, pues más de una vez se adivina que tal o cual animal retratado por el artista forma parte de su casa. En este sentido diríamos que en el ambiente de Murillo los perros fueron una constante, un elemento más de su hogar; en tanto que Zurbarán no parece ser aficionado a ellos. El protagonismo de las telas o de los cacharros de barro no deja espacio a los canes, incluso cuando por derecho propio tenían que estar allí, en la tela. Pudo Zurbarán colocar un perro en "la defensa de Cádiz", tal como lo hizo en "El hallazgo de la Virgen de Puig" o "El martirio de Santiago" con sólo una cabeza dotada de inteligentes ojos. Frente a la parquedad del extremeño, Murillo reparte perros de todas las razas en "El Hijo pródigo haciendo vida disoluta", "Bodas de Caná", "Tobías y el ángel", "Muchacho con perro", "Abuela espulgando al nieto", "Martirio de San Andrés", "Muchacho de la tartera", "Cena de Emaus", el "Sueño del Patricio", donde duermen él, ella y el perro. Es el mismo animal sin duda propiedad de Murillo, retratado en la "Sagrada Familia del pajarito" y en "El regreso del hijo pródigo".

Ahora bien, no siempre el perro tuvo un modelo. Al igual que esos horrendos caballos que llenan algunos lienzos, el perro fue retratado de memoria y su raza y rostro no quedaron firmemente reflejados. En el "Juicio de París" de P.P. Rubens un perro real "increpa" a un can echado cuya cabeza sin duda es una invención del artista.

Ninguna pintura -y ella fue según consignamos la inspiradora de este escrito, como la conservada en los Musées Royaux des Beaux Arts de Bruselas, obra de un artista anónimo flamenco del siglo XVII. Allí vemos a Doña Juana de Luna con los perros de la infanta Isabel. Son un total de 42, uno en brazos, dos sujetos y el resto que pululan en torno a la dama y exhiben los nombres al lado de su figura: Bruneta, Melisendra, Coquina, Breda, El viudo (con un mono sobre su lomo), Tirlila, Fidela, Píramo el Blanco, El Caballero, Si Señor, Ojos negros, Oriana, Polidoro, Lovillo, Petí, Berlina, Bolatín, Piramillo, Cadet, Patar, Sin nombre, Fidellila, Amoroso, Gunca, Oliva... Blancos, negros, marrones, manchados. Le acompañan dos loros o papagayos y un mono con una flor en la mano y un cinturón de cascabeles. Es toda una lección de zoología canina. El cuadro es original, con sus chuchos diversos, pacíficos, alborozados, traviesos... Como tantos otros que los pintores eternizaron sin que sepamos los lazos existentes entre el animal y el artista, para el cual, tal vez, significaba más el can que el paisaje o la figura humana. Porque el perro era suyo, formaba parte de su vida, le acompañaba en sus horas de trabajo y recibía una cuota de efecto que el amo quiso materializar retratándolo. Dentro de esta misma curiosidad que nos despierta el anónimo pintor de la infanta Isabel y sus perros, están los "Estudios de perros" por J. Brueghel que le sirvieron al artista para esbozar una treintena de canes en diversas posturas. Curioso resulta un cuadrito pequeño con seis perso- 
najes ajenos a los perros. (Das Kunst Historische Museum de Viena). Aquí mismo se conserva de James Ward, siglo XVIII, unos estudios de la naturaleza con cabezas y patas de animales, donde figura un perro.

Hay animales ornamentales, como esa cabeza que el inglés Joseph Wright de Derby trazó en la "Forja de hierro", salidos en ocasiones de los pinceles con la intención de acentuar el sosiego de un ambiente ("Las Meninas") o para subrayar la afición (cacería) del retratado: Thomas Gainsborough: Robert Andrews y su esposa", al que tanto se parece "El marqués de Arco Hermoso y su familia" de Cabral Bejarano con tata y niño que juega a base de un volatín con un chucho familiar. Este pintor costumbrista incluye frecuentemente perros en sus escenas consciente de que ellos deambulan con dueños o sin dueños por calles, plazas, iglesias, etc. como un elemento más del acontecer cotidiano. Es el fiel acompañante desde los tiempos primitivos que lo mismo marcha al lado de las cigarreras que cruzan el puente de Triana por Gonzalo de Bilbao que va al lado de unos campesinos de Carmona de Rodríguez Jaldón. Perros sin bravura integrados en un paisaje urbano o rural, como los del británico John Constable; o perros a través de cuya estampa se advierte que son capaces de poblar el escenario de ladridos, jadeos o dentelladas, tal cual vemos en ese lienzo que Paúl de Vost plasmó en "Fábula del perro y la presa", que exhibe (Prado) un can cruzando un puentecillo y al que se le acaba de caer al agua un trozo de carne. Perros que decoran, perros que acompañan, perros que cazan o que van a la caza y es el caso del Adonis de Ticiano. Desde siempre; en el Paraíso, en el Arca de Noé, en la Torre de Babel... Lucas Cranach en El Paraíso no dudó en enriquecer la soledad de Adán y Eva, aún sin hijos, con un galgo blanco echado a los pies de la mujer. Una decena de ellos, con un loro y un mono, colocó F. Francken en una babélica torre que se escapa hacia el cielo. El hombre lo ha hecho su amigo y compañero desde el inicio de los tiempos. Seguro que Abel, como buen pastor, poseía perros, al igual que el pastor de Brueghel en "La caída de Icaro". La soledad de la campiña se atenúa con la presencia del perro, que entiende todo lo que se le dice y habla con los ojos. El pastor, como el mendigo o el pícaro depositan su amor en un perro y ninguno tan encantador como el niño pastor de François Boucher que toca la gaita mientras su perrillo baila (Museo de Bellas Artes de Boston). Los murillescos pilletes de la tartera o la vieja que espulga al niño lo hacen en unión de un can, al igual que el mendigo o romero que pide a unos caballeros en el lienzo atribuido a Martín van Cleve el Joven representando El Escorial, o el perro que está con el Hechicero (especie de trilero) del Bosco.

La relación amo-animal es intensa, profunda, como de ser humano. De tal modo que la muerte del animal constituye un drama personal o familiar. Múltiples son los perros que dormitan al pie de sepulcros, recordamos ahora los dos que yacen a los pies de Gottfried IV, Conde de Arnsberg, muerto en 1371, en la 
catedral de Colonia, o los múltiples que yacen en el cementerio de canes de la sevillana finca de "Valparaíso" donde algunos sitúan la escena del sofá del "Don Juan Tenorio". Alude Argote de Molina a esa fidelidad canina y a la mucha literatura que ellos han inspirado, y cuenta que don Lorenzo Suárez de Figueroa, Maestre de Santiago, poseyó un perro llamado "Amadis", en memoria del cual ordenó poner uno de alabastro a los pies de su sepulcro en la sevillana iglesia de Santiago con la leyenda "Amado Amadis". La imagen cambia si pensamos en la también yacente figura de la "Venus de Urbino" (Tiziano) con un tono en las mórbidas carnes que se prolonga en el pelaje del faldero ovillado a sus pies, o el que se acurruca bajo la mano de "Danae recibiendo una lluvia de oro" del mismo artista.

Sorprende el entendimiento que llega a establecerse entre el dueño y el animal. La complicidad, y sagacidad las resalta Murillo en "El muchacho con perro", o Goya con el perrillo que salta intentando llamar la atención a la joven que lee una carta. Son muchos de estos chuchos, animales de interior, de intimidad, propios para una atmósfera hogareña. Tal el peludo cachorro de inteligentes ojos que Jan van Eyck incorporará al retrato de Giovanni Arnolfini y su esposa de avanzado embarazo; o el que Jesús Niño, azuza con un pajarillo en la mano ("Sagrada Familia del pajarito") o el que también Murillo sitúa pulcro, lustroso y hasta sospechamos que perfumado, con lazo y cascabel a los pies de don Justino de Neve. Familiar y con cascabeles delatores de su presencia, resulta el perrillo de ojos cual perlas que reposa en el Tríptico de Jan de Witte sobre el bolso de una dueña que ora ante la Virgen. Nada más familiar que el perro blanco que Johan Zoffany insertó en "La familia Sharp" (grupo musical) y el también blanco que llama la atención de "El duque Federico Gonzaga" por Tiziano o el del retrato de tres niños por José María Romero (Casón de Buen Retiro) que es como un juguete más de los infantes. De juguete, cual un Chihuahua el perrillo que sostiene con su mano izquierda la "Jeune Dame" de Frans Van Mieris le Vieux. En la familia Sharp los componentes de la orquesta, unos músicos con sus instrumentos, y otros cantantes, componen un grupo feliz, cuya serena atmósfera subraya el animal echado que, sin duda, no se alteraba cuando el conjunto entraba en acción.

Esta placidez y mansedumbre de un perro hogareño, que puede ser cortesano o burgués, sin problemas, como son los de Anton. van Dick en "Los hijos de Carlos I" y en el Príncipe Ruperto del Palatinado (Viena), o los de W. Hogarth cuando critica las costumbres matrimoniales de la aristocracia, queda violentamente destrozada por el salvajismo de los cancerberos de Frans Synder (Prado) cuyos ladridos parecen escucharse mientras persiguen a un aterrorizado jabalí, o los de Jan I van Kessel que veloces, acaban de sorprender a una alocada bandada de aves (Musées royaux de Bruselas). $\mathrm{O}$ los galgos y podencos de Adrien Brou- 
wer que acosan y desgarran a un ciervo que salta hacia el cielo formando con la feroz jauría un triángulo dramático (Prado). También Bernard van Orley (Statens Museum for Kunst, Copenhague) plasmó una escena similar: el jabalí escapa acosado por un caballero que lo hiere con su espada en compañía de perros, uno de los cuales ha quedado muerto y otro luce un escaupil (camisa acolchada). Persiguen, decíamos, a unos jabalíes, pero en Botticelli ("La visión de Nastagio") la aperreada es una dama desnuda en cuyas nacaradas carnes un blanco mastín hunde sus dientes. A.J.P. Verdussen le atrajo los motivos cinegéticos, con perros que unas veces corren en pos de un ciervo, y otras retornan de la cacería despojados de toda fiereza y enfrascados en juegos o en la concienzuda tarea de espulgarse una pata. El tema de la cacería atrajo también a Lucas Cranach; su "Cacería de ciervos" muestra una floresta y un río con barca en la que navegan damas y caballeros. Ballesteros apostados tras los árboles y jinetes lanza en ristre acosan a los animales. Hay dos versiones, en una se ve una jauría atada, en otra los ciervos huyen y hay perros heridos. Espléndidos perros cazadores son los de Gustave Coubert en el Museo de Bellas Artes de Boston.

En las cacerías se utilizaban lebreles, mastines o alanos, llamados estos últimos así a semejanza de los bárbaros invasores de España. Tales tipos de animales los usaron Grecia y Roma, y en las campañas bélicas del siglo XVI, incluso en la Conquista de América, cuyos aborígenes se vieron a veces aperreados por unos canes preparados para reconocer, perseguir y cazar al enemigo. Protegidos por escaupiles tal como los muestra Jerónimo Bosco en "Las tentaciones de San Antonio", donde lucen también caperuzas y llegando a cobrar sueldos como un peón, algunos alcanzaron la fama y sembraron el pavor entre los indios que los vieron enormes, fuertes, de lenguas colgantes, ojos amarillos que derramaban fuego, jadeantes e inquietos. Tal la información de Sahagún. Un indio le duraba a uno de estos sabuesos el tiempo que se tardaba en rezar un credo. Piadoso cálculo, que explica lo que es llevar una vida aperreada. Para el pobre indio el animal, que luego haría su gran amigo, resultaba algo infernal, demoniaco, como esa cabeza de ojos sanguinolentos que arranca las ropas a San Pablo en el lienzo de Andrés Rubira (Academia de San Fernando).

Al lado de estos perros crueles y en movimiento, encontramos los que siendo también de caza y, por ende terribles, llegado el momento, posan pacíficos y decorativos con un grupo de personas o con personajes regios o significativos. Tal el caso del bello ejemplar de mirada amorosa que Tiziano une a la figura de Carlos V o que Velázquez incluyó en el retrato del Cardenal Infante don Fernando. Murillo representó otro de porte fiero en el retrato de don Andrés de Andrade Manso; mientras que Goya prefirió dibujarlo encogido, dormido, junto a la escopeta real, ajeno a la realeza de Carlos III, pero que en Carlos IV mira atentamente al amo. Perros cazadores acompañan a Joaquín Domínguez Bécquer en su 
autoretrato. Otras veces no es un perro cazador, sino una manada de negras o manchadas siluetas, como las que caminan al lado de "Cazadores en la nieve" de Pieter Brueghel, y que parecen retornar cansados después de una agitada jornada de caza, o los que lleva don Antonio Hurtado de Mendoza con su montero (Murillo), o los que están con los cazadores junto a un pozo de Andrés Cortés, que también los utilizó en sus temas sobre Feria de Sevilla al igual que Manuel Rodríguez de Guzmán. En la pintura británica del XVIII abundan las escenas de caza. La caza es una diversión y un deporte distinguido al que concurren reyes y nobles, caballos y perros como en "La Cacería de Grovesnor" de George Stubbs, donde casi un medio centenar de canes en agitado movimiento acosan a un ciervo, que nueve caballeros han acorralado. La escena de grupo se suaviza en el mismo pintor cuando lo que representa es a la duquesa de Richmond y a Lady Luisa Lennox viendo ejercitarse a los caballos de carrera del duque de Richmond.

Perros con dueños, perros sin dueños; perros mansos, perros sanguinarios, perros cortesanos, perros burgueses, perros hogareños, perros callejeros. Sin duda que pertenecen a alguien los perros que Pieter Brueghel introduce en la matanza de los Inocentes, o los de la "Kermesse" campesina de David Teniers (Bruselas y Viena), o los que pelean, divagan o participan en otras tantas escenas populares, verbi gracia "El invierno " de Abel Grimmer o "La Nevada" de Goya. ¿Tienen dueños los que vemos en el Arenal de Sevilla?. Dentro de la abigarrada escena, cobijada en un cielo toledano del Greco, Sánchez Coello nos dejó en el puerto sevillano tres chuchos: uno blanco retozón y dos que en la orilla trianera escuchan a un hombre tocar la guitarra. Recuerdan al que P. Bril hace correr en su lienzo "El Puerto". Juguetones como estos perros urbanos son los campestres que Jean Brueghel (Prado) introduce en el cortejo "Bodas campesinas" junto con chiquillos, músicos, vencejos, gallos y gallinas; o los dos, blanco y negro, que Pieter Brueghel sitúa disputándose un hueso en "Proverbes flamands". También un hueso o un palo entretiene a dos perrillos manchados en el lienzo de David Teniers "La Colección del Archiduque Leopoldo-Guillermo" (Kunsthistorisches Museum, Viena). Carácter de perro-mascota ofrece el can que metido en el grupo se divisa en el lado derecho de la famosa "Ronda nocturna" de Rembrandt, o el que salta y ladra gozoso y excitado en "Episodio de la Jornada de septiembre 1830" de Barón Gustaf Wappers (Musées royaux de Bélgica).

Delicioso por la ternura del adolescente, y del can resulta en G. Romney un niño con perro, que recuerda a lo que vemos en el óleo de Joshua Reynolds representando a Miss María Gideon y su hermano William. El chucho alza dócil y cariñosamente su rostro hacia el adolescente. Del mismo autor vemos un perrillo lanudo y juguetón que J. Reynolds pone de compañero a la Condesa de Spencer y su hija. Juguetones lucen así mismo los animales que Sir David Wilkie 
incorpora a la "Feria de Pitesie" en una escena abigarrada digna de un primitivo. Dos perrillos igualmente traviesos ocupan el centro de la galería de pinturas del archiduque Leopoldo Guillermo pintada por David II Teniers (Prado). Por su parte David III Teniers nos legó un Carlos II niño adornado de espada y Toisón, al que rodean dos divertidos perrillos.

Están en todas partes y a cualquier hora; dentro de las iglesias; en las plazas; en los palacios; en las chozas; con reyes y pordioseros. Ni siquiera faltan a la cita en instantes cumbres de la religión cristiana: Anunciación, Adoración de los Reyes, Sagrada cena, Calvario... Tiene mucha gracia el perrillo que descansa junto a María en la Anunciación de un discípulo de Juan de Flandes (Palencia). La presencia extraordinaria del Angel anunciador no ha impresionado lo más mínimo al cancerbero, que sigue echado, inmutable, en tanto que la Virgen recibe el mensaje sobrecogida.

De exorno, al margen de la acción, reposa en primer término un lebrel blanco en la "Adoración de los Reyes" de Fray Filippo Lippi. En la "Adoración de los Reyes" de Rogier Van der Weyden vemos un galgo blanco echado, mientras que Jérôme Bosh lo coloca sentado en sus cuartos traseros ("Adoración de los Magos"). Gentil da Fabriano, en una "Adoración de los Reyes" de 1423 efigió un chiquillo que se entretiene con las espuelas de un Rey Mago y a su lado un perro con un bozal (Los Uffizi). Dos de raza distinta figuran en la "Adoración de los Magos" de Jan Brueghel. Excitada o jadeante parece ese cabeza canina que Luis de Varga hará asomar por debajo de un pastor de su "El nacimiento de Cristo" de la Catedral de Sevilla. Curioso o husmeante se vuelve hacia una pastora que porta un cesto que de la sensación de interesarle en "La adoración de los pastores" de la misma Catedral por Francisco Antolinez; mientras que en la misma escena, en el mismo templo, parece querer jugar o atender los gestos de un angelito. Tampoco inquieta a otro perrillo blanco el ángel que comunica a Joaquín el nacimiento de María (Q. Metsys: Tríptico con la familia de Santa Ana), ni la presencia de Jesús en casa de Marta y María. María, cuenta San Lucas, "se sentó a los pies del Señor para escuchar sus palabras. Marta, en cambio, se distraía con el mucho trajín" ¿Y el perro? El evangelista no lo recuerda, claro, pero A. Grimer lo pinta inconsciente a la trascendencia del instante y al afán de Marta, echado enmedio de la habitación. ¿Estaba allí? ¿O fue un subterfugio del pintor para rellenar un espacio vacío?

En la Sagrada Cena del Maestro de la Abadía de Dilighem, al igual que en la Sagrada Cena de Tiziano, un can roe tranquilamente bajo la mesa un hueso ajeno al misterio y drama que se gesta en la habitación. En idéntica tarea se entretiene otro de la "Kermesse flamenca" debida a Brueghel. De este mismo autor son los cinco perros de diversas razas que figuran en "La matanza de los inocentes".

Incluso en la Crucifixión hay perros; uno blanco entre las piernas de un judío 
que alza la cruz en el lienzo de Wolf Huber; otro, salpicado de pintas, que lame el brazo de un esqueleto en la Crucifixión de Lucas Cranach; y un conjunto de ellos en actitud espectadora contemplando el entierro de Cristo de Geertgen von Haarlem (Viena).

El tema es casi inagotable. Cualquiera que visite en Madrid el Museo Thyssen Bornemisza tropezará con perros en cuadros de Juan Brueghel, Frans van Miers, Giovanni Paolo Panini, Giuseppe María Crespi, Vittore Carpaccio, Lucas van Valkenborch, Jan Havicksz Steen, Davied Teniers, Peter Neeffs, Pieter Hendvicksz, Emanuel Witte, Jacob Lucasz, Joannes Siberechtc, Philips Woowermans, Nicolás Bernard Lepicié, John Sloan, Otto Dix, etc. Aparecen en el regazo de una dama, en la balumba de la expulsión de los mercaderes del templo, en la piscina probática, en las matanzas de los Inocentes, en fiestas campesinas, en bodas campestres, en el mercadoy en el Consejo de Amsterdam, etc. Encogidos en unos brazos, husmeantes, saltando, retozones, decorando el ambiente, etc.

Los traídos a colación hasta el momento, que se podrían multiplicar y de los cuales un entendido nos daría sus razas, son perros que viven dentro de los cuadros, insertos en la escena, bien en reposo, bien en movimiento. Pero a veces el can se desliga de lo que le rodea y pone su atención, con mirada desconfiada, en el observador. Sucede así en el animal blanco y marrón, compañero de San Pablo en Efeso de Martín de Vos.

Ninguno de estos animales constan con sus nombres, les distingue la raza, son meros elementos de adorno, complementarios. Salvo cuando el pintor realiza el retrato del animal, como en el caso de "Ringwood", perro zorrero de Brocklesby pintado por George Stubbs, o los mencionados acompañantes de doña Juana de Lunar, los cuales lucen sus apelativos. Se les quiso retratar para que cuando la infanta Isabel fuera mayor los evocase y los volviera a llamar vanamente...: Bruneta, Melisendra, Polidoro, Amoroso... 


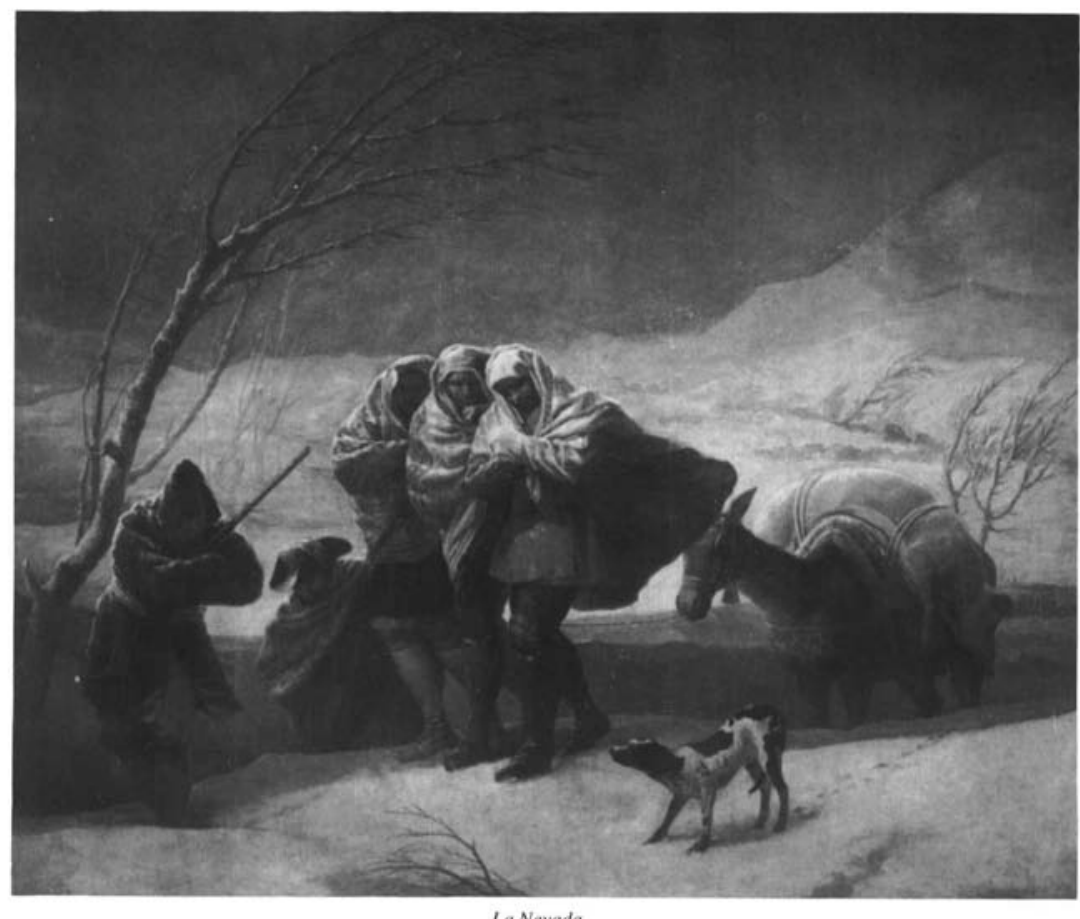




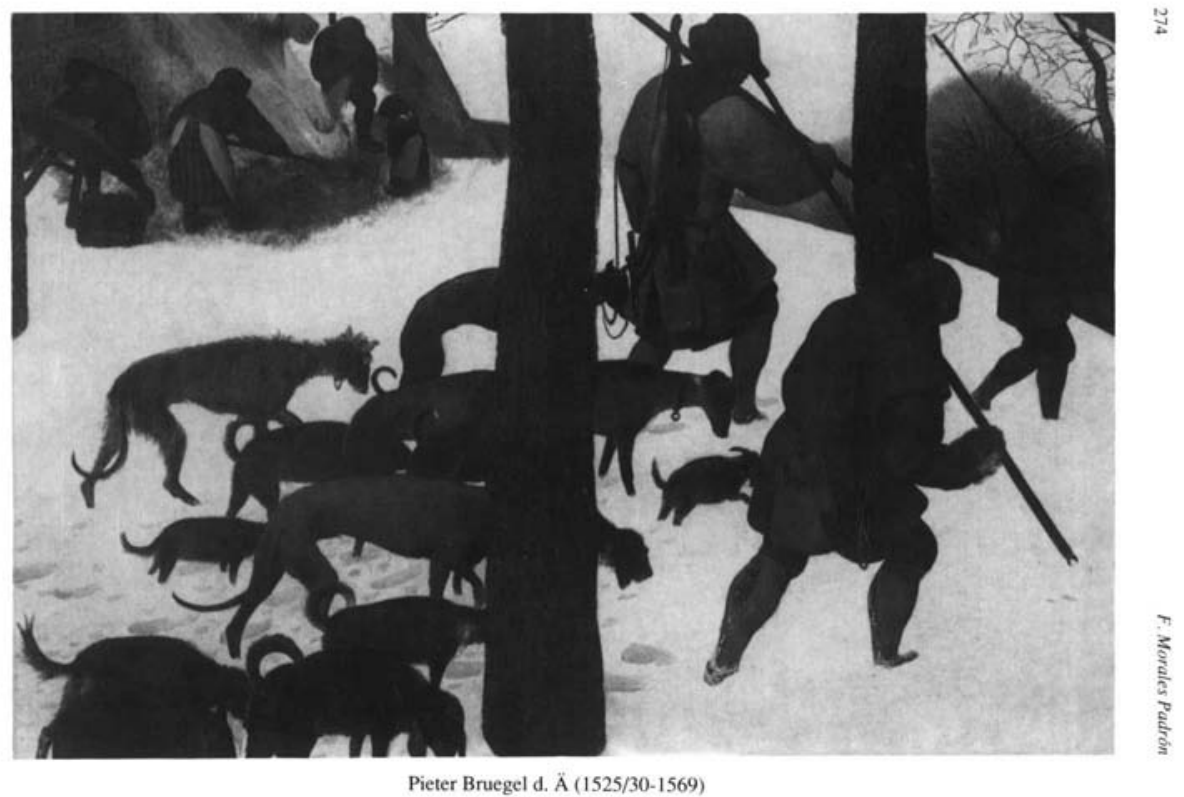

